\title{
Vicilins (7S storage globulins) of cowpea (Vigna unguiculata) seeds bind to chitinous structures of the midgut of Callosobruchus maculatus (Coleoptera: Bruchidae) larvae
}

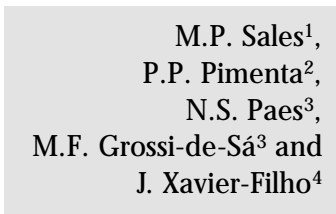

Correspondence

M.P. Sales

Departamento de Bioquímica

UFRGN

59072-970 Natal, RN

Brasil

Fax: +55-84-211-9208

E-mail: msales@cb.ufrn.br

Research supported by CNPq, CAPES and PRONEX.

Received January 25, 2000 Accepted September 19, 2000

\author{
1Departamento de Bioquímica, U niversidade Federal do Rio Grande do Norte, \\ Natal, RN, Brasil \\ ${ }^{2}$ Centro de Pesquisa Rene Rachou, Belo Horizonte, MG, Brasil \\ ${ }^{3}$ Centro Nacional de Recursos Genéticos e Biotecnologia, EM BRAPA, \\ Brasília, DF, Brasil \\ 4Laboratório de Química e Função de Proteínas e Peptídeos, \\ Centro de Biociências e Biotecnologia, Universidade Estadual do Norte Fluminense, \\ Campos dos Goytacazes, RJ, Brasil
}

\section{Abstract}

The presence of chitin in midgut structures of Callosobruchus maculatus larvae was shown by chemical and immunocytochemical methods. Detection by Western blotting of cowpea (Vigna unguiculata) seed vicilins (7S storage proteins) bound to these structures suggested that $C$. maculatus-susceptible vicilins presented less staining when compared to C. maculatus-resistant vicilins. Storage proteins present in the microvilli in the larval midgut of the bruchid were recognized by immunolabeling of vicilins in the appropriate sections with immunogold conjugates. These labeling sites coincided with the sites labeled by an anti-chitin antibody. These results, taken together with those previously published showing that the lower rates of hydrolysis of variant vicilins from $C$. maculatus-resistant seeds by the insect's midgut proteinases and those showing that vicilins bind to chitin matrices, may explain the detrimental effects of variant vicilins on the development of C. maculatus larvae.

\section{Introduction}

Cowpea (Vigna unguiculata) is a legume cultivated in most tropical regions of the world (1). In Brazil, cowpea is mostly cultivated in the northeastern part of the country and is the main protein source for poor populations (2). Cowpea seeds are heavily infested with Callosobruchus maculatus (Coleoptera: Bruchidae) larvae when in storage. Screening of the cowpea germplasm collec-

\section{Key words}

- Bruchid beetles

- Callosobruchus maculatus

- Cowpea seeds

- Vigna unguiculata

- Vicilins (7S storage proteins)

- Immunolocalization

- Midgut tion of the International Institute of Tropical Agriculture (IITA), Ibadan, Nigeria, allowed the identification of sources of natural resistance to C. maculatus (3). One of these, $\mathrm{TVu}$ 2027 , led to the development of several lines such as IT81D-1032, IT81D-1064 and IT81D1045 , that show different levels of resistance to the bruchid (4). The resistance of the seeds of these varieties has been attributed to various factors mostly of a chemical nature. Gatehouse et al. (5) and Gatehouse and Boulter (6) sug- 
gested that high levels of trypsin inhibitors in TVu 2027 seeds were responsible for the observed resistance to C. maculatus. However, other workers (7-10) did not find a significant correlation between the levels of trypsin or cysteine proteinase inhibitors or even $\alpha$-amylase inhibitors in cowpea seeds and their susceptibility or resistance to infestation with $C$. maculatus. More recent studies suggest that the resistance of IT81D-1045 seeds to C. maculatus is due to variant forms of vicilins ( $7 \mathrm{~S}$ storage proteins) which are resistant to digestion by midgut proteinases and possibly limit food supply to the larvae (11-13). The mechanism of resistance due to variant vicilins seems to be also linked to their chitin-binding power, a recently discovered property (14-17). This mechanism may be similar to the one attributed to the action of chitin-binding proteins ( $\mathrm{N}$-acetylglucosamine-specific lectins, chitinases, hevein and antimicrobial peptides) which are involved in defense mechanisms of plants against insects and pathogens (18).

The purpose of the present study was to determine the presence of chitin (or chitincontaining structures) in the midgut of $C$. maculatus larvae utilizing both chitin and vicilin probes.

\section{Material and Methods}

\section{Seeds}

Cowpea ( $V$. unguiculata) seeds of the $C$. maculatus-susceptible cultivar CE-31 were supplied by Centro de Ciências Agrárias, Universidade Federal do Ceará, Fortaleza, CE, Brazil. C. maculatus-resistant cowpea seeds of the Nigerian line IT81D-1045 were obtained from IITA through Centro Nacional de Pesquisa do Arroz e Feijão-Embrapa, Goiânia, GO, Brazil.

\section{Insect}

C. maculatus insects were originally sup- plied by Dr. J.H.R. Santos (Centro de Ciências Agrárias, Universidade Federal do Ceará). Permanent colonies of the insect were established on susceptible and resistant cowpea seeds and reared at $28-30^{\circ} \mathrm{C}$ and $55-$ $60 \%$ relative humidity.

\section{Isolation of vicilins}

Vicilins were prepared from cowpea seeds by the procedure of Macedo et al. (19). Ground meal extracted with $50 \mathrm{mM}$ borate buffer, $\mathrm{pH} 8.0$, for $30 \mathrm{~min}$ at room temperature was centrifuged $\left(30 \mathrm{~min}\right.$ at $\left.8,000 \mathrm{~g}, 5^{\circ} \mathrm{C}\right)$ and soluble proteins were fractionated by ammonium sulfate precipitation. The $70-90 \%$ saturation fraction was dialyzed against water, freeze-dried and chromatographed on a Sephacryl S-200 column $(3 \times 40 \mathrm{~cm})$ equilibrated and eluted with the same buffer as used for extraction. The vicilin-rich fractions were recovered and chromatographed on a DEAE-Sepharose column $(2 \times 20 \mathrm{~cm})$ equilibrated with $50 \mathrm{mM}$ Tris- $\mathrm{HCl}, \mathrm{pH} 8.0$, and eluted with a $\mathrm{NaCl}$ gradient $(0$ to $1 \mathrm{M})$ in the same buffer. The vicilin-rich fractions were recovered and submitted to chromatography on a Sephacryl S-400 column $(2.5 \times 70$ $\mathrm{cm}$ ) in $0.1 \mathrm{M}$ Tris- $\mathrm{HCl}, 0.25 \mathrm{M} \mathrm{NaCl}, \mathrm{pH} 8.0$. Fractions containing vicilins were dialyzed against water and freeze-dried.

\section{Protein determination}

The dye-binding method of Bradford (20) was used for protein determination using bovine serum albumin as standard. Occasionally, measurement of absorbance at 280 nm was also used.

\section{Antiserum preparation}

Antisera against chemically deglycosylated purified vicilins were prepared by immunization of white rabbits according to established methods. Purified antisera were obtained by affinity chromatography of the 
crude immune sera on a protein A column (protein A bound to Sepharose CL-4B). Preimmune sera were collected before immunization and used as control.

\section{SDS-PAGE and Western blotting}

Purified vicilins were separated by $13 \%$ SDS-PAGE by the method of Laemmli (21) and transferred to nitrocellulose membranes by the method of Towbin et al. (22). The immunoblots were made with the polyclonal antibodies against purified vicilins as described above. Binding was visualized with a horseradish peroxidase-conjugated secondary antibody (Bio-Rad Laboratories, Richmond, CA, USA) according to manufacturer instructions.

\section{Chemical test for chitin}

Larvae were dissected under magnification in cold $0.15 \mathrm{M} \mathrm{NaCl}$ with the help of tweezers and midguts were separated from the windpipes and Malpighian tubes. Midguts were perforated and luminal contents were aspirated and reserved. Midguts were then thoroughly washed to remove remaining luminal contents. The presence of chitin in C. maculatus larval midgut and luminal contents was ascertained by the von Wisselingh color test (23). This qualitative test detects chitosan produced after treatment of the chitin-containing materials with saturated $\mathrm{KOH}$ for $15 \mathrm{~min}$ at $160^{\circ} \mathrm{C}$. After reaction, the presence of chitin was observed with a KI/ iodine solution. Controls employing cellulose (-) and lobster chitin (+) were used.

\section{Chitin-binding assays}

Twenty larvae reared in cowpea seeds (CE-31) were dissected under magnification in cold $0.15 \mathrm{M} \mathrm{NaCl}$ with the help of tweezers. After exposure, midguts were homogenized with $50 \mathrm{mM}$ sodium phosphate buffer, $\mathrm{pH} 7.6$, and centrifuged at $10,000 \mathrm{~g}$. The pellet was washed with $0.1 \mathrm{~N} \mathrm{HCl}$ solution to remove diet proteins possibly retained by chitinous structures. Washed pellets were equilibrated with $50 \mathrm{mM}$ phosphate buffer, $\mathrm{pH}$ 7.6, before being used for the observation of vicilin binding. Pellets containing 20 midguts were immersed in solutions ( $2 \mathrm{mg} /$ $\mathrm{ml}$ in $50 \mathrm{mM}$ phosphate buffer, $\mathrm{pH}$ 7.6) of both resistant (IT81D-1045) and susceptible (CE-31) cowpea seed vicilins and left to stand for $10 \mathrm{~min}$ with gentle shaking. The material was then centrifuged and the two pellets were washed with $50 \mathrm{mM}$ sodium phosphate buffer, $\mathrm{pH}$ 7.6, to remove unbound vicilins. Bound proteins were eluted with soluble chitosan and $0.1 \mathrm{~N} \mathrm{HCl}$ and analyzed by Western blotting as described before.

\section{Immunocytochemistry}

Larvae (3rd instar, 18 days) of insects reared in susceptible (CE-31) seeds were dissected and the midguts separated. Small larvae (18 days) of insects reared in resistant (IT81D-1045) seeds were used without dissection. Both types of materials were used for immunocytochemical analysis. These materials were fixed in 3\% paraformaldehyde $/ 0.5 \%$ glutaraldehyde in $0.5 \mathrm{M}$ sodium cacodylate buffer, $\mathrm{pH} 7.2$, for $24 \mathrm{~h}$, with alternate shaking and vacuum treatments. The material was then washed in sodium cacodylate buffer (3 times, $15 \mathrm{~min}$ each), dehydrated in a series of ethanol/water mixtures at 10, 20, 30, 50, 70, 90 and 100\% ethanol and then embedded in hydrophilic LR White acrylic resin. Midgut microtome sections were prepared for indirect immunolabeling using anti-chitin $\operatorname{IgG}(1: 2000)$. The distribution of specifically bound anti-vicilin (1:1000) in the sections was determined using secondary antibodies conjugated with colloidal gold $(5 \mathrm{~nm})$. An anti-chitin antibody raised in rabbits (1:2000) was used to detect chitin followed by a secondary antibody conjugated with streptavidin alkaline 
Figure 1 - A, Representative Western blotting analysis showing the differential binding of vicilins to isolated membranous structures of larval Callosobruchus maculatus midgut. Lane 1 , Susceptible vicilins (control); lane 2, resistant vicilins (control); lane 3 , susceptible vicilins eluted with chitosan; lane 4, resistant vicilins eluted with chitosan; lane 5 , susceptible vicilins eluted with $0.1 \mathrm{~N} \mathrm{HCl}$; lane 6, resistant vicilins eluted with $0.1 \mathrm{~N} \mathrm{HCl}$. B, SDS-PAGE of purified vicilins. Lane 1 , Susceptible vicilins; lane 2 , resistant vicilins. The arrows indicate the $45-\mathrm{kDa}$ molecular mass. phosphatase and the reaction was amplified with rhodamine. Controls used were midgut sections with or without immunogold and pre-immune sera.

\section{Results and Discussion}

Vicilins consist of multi-subunit combinations with molecular masses between 20.1 and $94 \mathrm{kDa}$ (24). Combination of multiple structural genes and extensive post-translational processing results in a high degree of polymorphism for these proteins (25). In legume seeds, vicilins exhibit a considerable amount of sequence homology and microheterogeneity and may contribute to plant defense mechanisms (26). The 7S globulins, also known as vicilins, are the major cowpea storage proteins, which are highly heterogeneous and are also encoded by a multigene family (27). Here cowpea vicilins from the seeds of the cultivars CE-31 and IT81D1045 were purified by gel filtration through Sephacryl S-200 followed by ion-exchange chromatography on DEAE-Sepharose (data not shown). Three main bands of vicilin polypeptides isolated from resistant and susceptible cowpea seeds were observed under
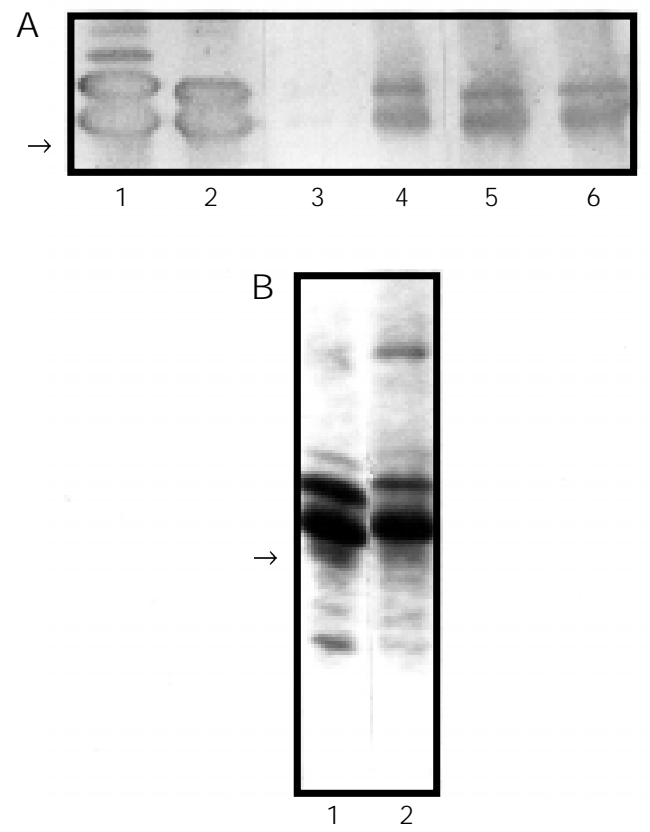

denaturing conditions (SDS-PAGE). Coomassie blue staining showed that both proteins have major molecular masses between 45 and $66 \mathrm{kDa}$ (Figure 1B) in agreement with data previously reported by several groups $(19,24,27,28)$. Sales et al. (12) and Macedo et al. (19) have shown that these proteins are desorbed by different salt concentrations from hydroxyapatite and DEAESepharose. These findings may reflect the different binding strengths of both vicilins towards the matrices that could be due to differences in isoelectric points and microheterogeneity.

The presence of chitin in the midgut of $C$. maculatus larvae was first shown by a chemical test and by in vitro assays. The color test (von Wisselingh test) for the qualitative determination of chitin was used to detect the presence of this compound in the luminal fluid and membranous structures of C. maculatus larvae. After treatment with $\mathrm{KOH}$, the pellets were treated with a KI/iodine solution. The appearance of a brown color was indicative of the presence of chitin. A positive test was confirmed by the addition of $0.1 \% \mathrm{H}_{2} \mathrm{SO}_{4}$ when the color turned violet. The von Wisselingh color test for chitin was positive for both the luminal fluid content and membranes of the larval midgut.

In the present study, representative immunoblot analyses were performed showing the differential binding of vicilins to membranous structures of the larval midgut. Resistant and susceptible vicilins were found to bind to isolated membranous structures from C. maculatus larvae and sequentially eluted by chitosan and $0.1 \mathrm{~N} \mathrm{HCl}$. Sales et al. (14) reported that when resistant and susceptible vicilins were chromatographed on a chitin column they bound to this matrix. Both vicilins showed the same pattern of sequential subunit elution by $\mathrm{N}$-acetylglucosamine and chitosan, but subunits from IT81D-1045 were more strongly bound to the chitin matrix. In our assays, resistant vicilins showed a stronger binding signal in the eluate from soluble 
chitosan while for susceptible vicilins the signal was weaker. Both vicilins showed a strong signal in the $0.1 \mathrm{~N} \mathrm{HCl}$ eluates. These results suggest that membranous structures of the C. maculatus larval midgut have chitin constituents and that the binding pattern for resistant vicilins differs from the pattern observed for susceptible vicilins (Figure 1A).

Comparison of the size of larvae grown on susceptible (Figure 2A) and resistant (Figure 2B) cowpea seeds after 18-day infestation showed a substantial inhibition of the growth of larvae fed on resistant seeds. We utilized 3rd-instar larvae (18 days after egg hatching) that were reared on susceptible (CE-31) cowpea seeds. These larvae weighed $9.0 \mathrm{mg}$ and were $3.0 \mathrm{~mm}$ long on average. Larvae at 18 days after egg hatching and not quite fully developed (average mass of 0.9 $\mathrm{mg}$ and $1.0 \mathrm{~mm}$ in length) were obtained from infested resistant cowpea seeds (IT81D1045 line). In order to investigate the presence of chitin and associated effects of vicilins on larval development, we examined midgut tissues of larvae fed on susceptible cowpea seeds and whole larvae that had fed on resistant seeds.

The structure of the larval midgut of $C$. maculatus allowed to develop for 18 days on cowpea seeds, as seen at low magnification in toluidine blue-stained sections (Figure 3A), was similar to that observed by Vats (29) for Zabrotes subfasciatus, Callosobruchus annalis, Caryedon serratus and Bruchidius saundersi larvae. This investigator showed that epithelial cells that form the gut wall have a normal polar appearance, with prominent nuclei and numerous small translucent vacuoles/droplets towards the apical side. The epithelial cells have microvilli and the lumen contains stained material that may be food particles in the process of being digested.

After immunostaining with antibodies to chitin (Figure 4), we found strong immunolabeling of the apical part of microvilli from the midgut epithelium indicating the pres-

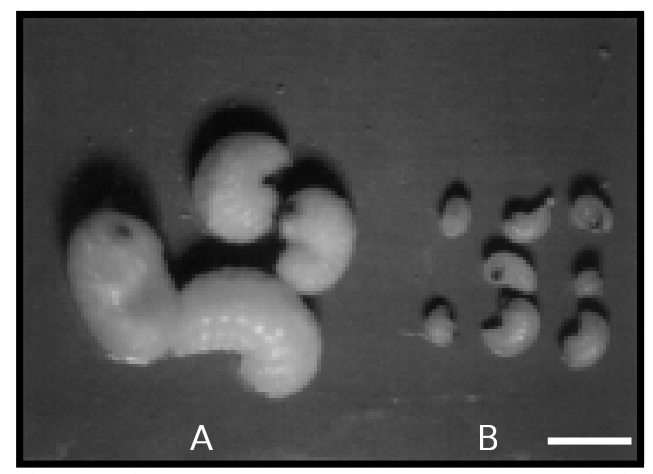

Figure 2 - Inhibitory effect of resistant seeds on the size (growth) of Callosobruchus maculatus larvae. A, Larvae (3rd instar, 18 days old) of insects reared on susceptible (CE-31) seeds. B, Larvae (18 days old) of insects reared on resistant (IT81D-1045) seeds. Magnification: 200X; bar: $500 \mu \mathrm{m}$.

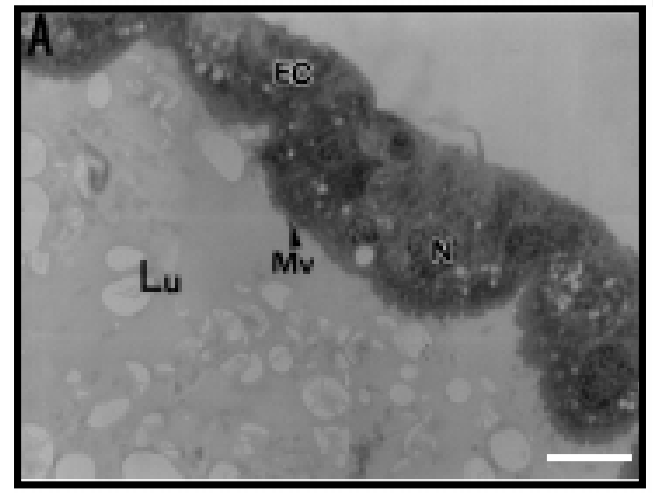

Figure 3 - Immunohistochemical detection of vicilins in microsections of the larval midgut of Callosobruchus maculatus reared on resistant (IT81D-1045) cowpea seeds. A, Microsection of the midgut stained with toluidine blue. B, Microsection of the midgut immunolabeled with antivicilin IgG. $\mathrm{Lu}=$ Lumen, $\mathrm{Mv}=$ microvilli, $\mathrm{N}=$ nuclei, $\mathrm{EC}=$ gut epithelial cells. Magnification: 3,500X; bar: $30 \mu \mathrm{m}$.
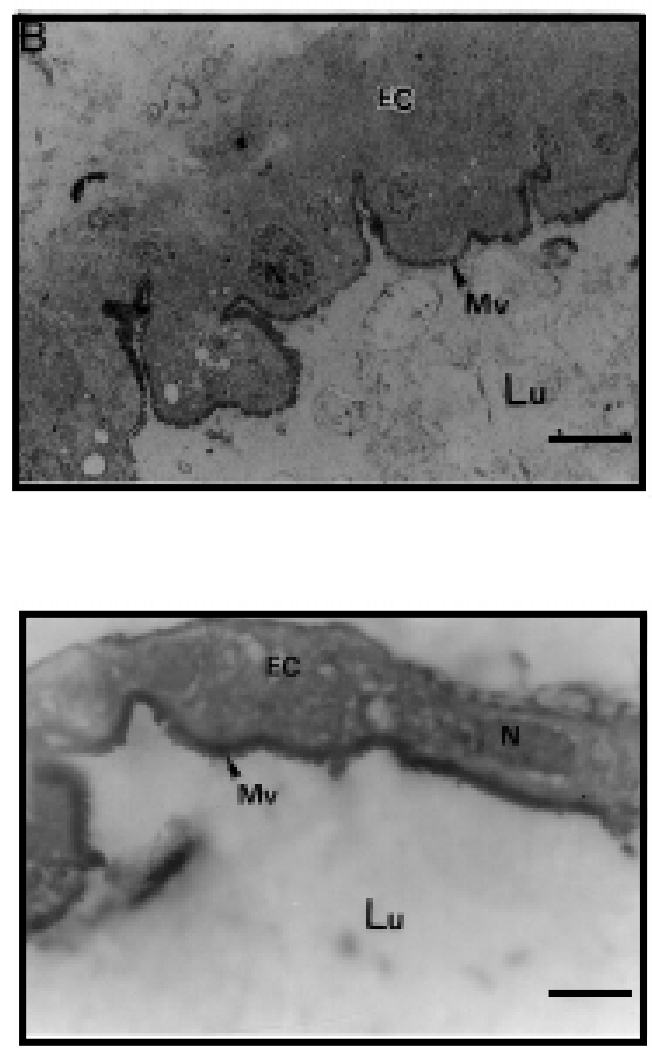

Figure 4 - Immunohistochemical detection of chitin in microsections of the larval midgut of Callosobruchus maculatus reared on resistant (IT81D-1045) cowpea seeds with anti-chitin IgG, visualized with alkaline phosphatase and amplified with rhodamine. $\mathrm{Lu}=$ Lumen, $\mathrm{Mv}=\mathrm{mi}-$ crovilli, EC = gut epithelial cells, $\mathrm{N}=$ nuclei. Magnification: 7,800X; bar: $20 \mu \mathrm{m}$. 
ence of chitin or chitinous structures in the larval midgut. Immunostaining with antivicilin IgG, used as a probe for chitin, also showed strong immunolabeling of the apical part of the microvilli, but without apparent staining of the nuclei or epithelial cells. Labeling of vicilins was not much visible in the gut contents of the lumen (Figure 3B).

The structure of the midgut of C. maculatus larvae allowed to develop for 18 days on resistant cowpea seeds is shown in Figure $5 \mathrm{~A}$ and $\mathrm{B}$. Sections cut through the midgut
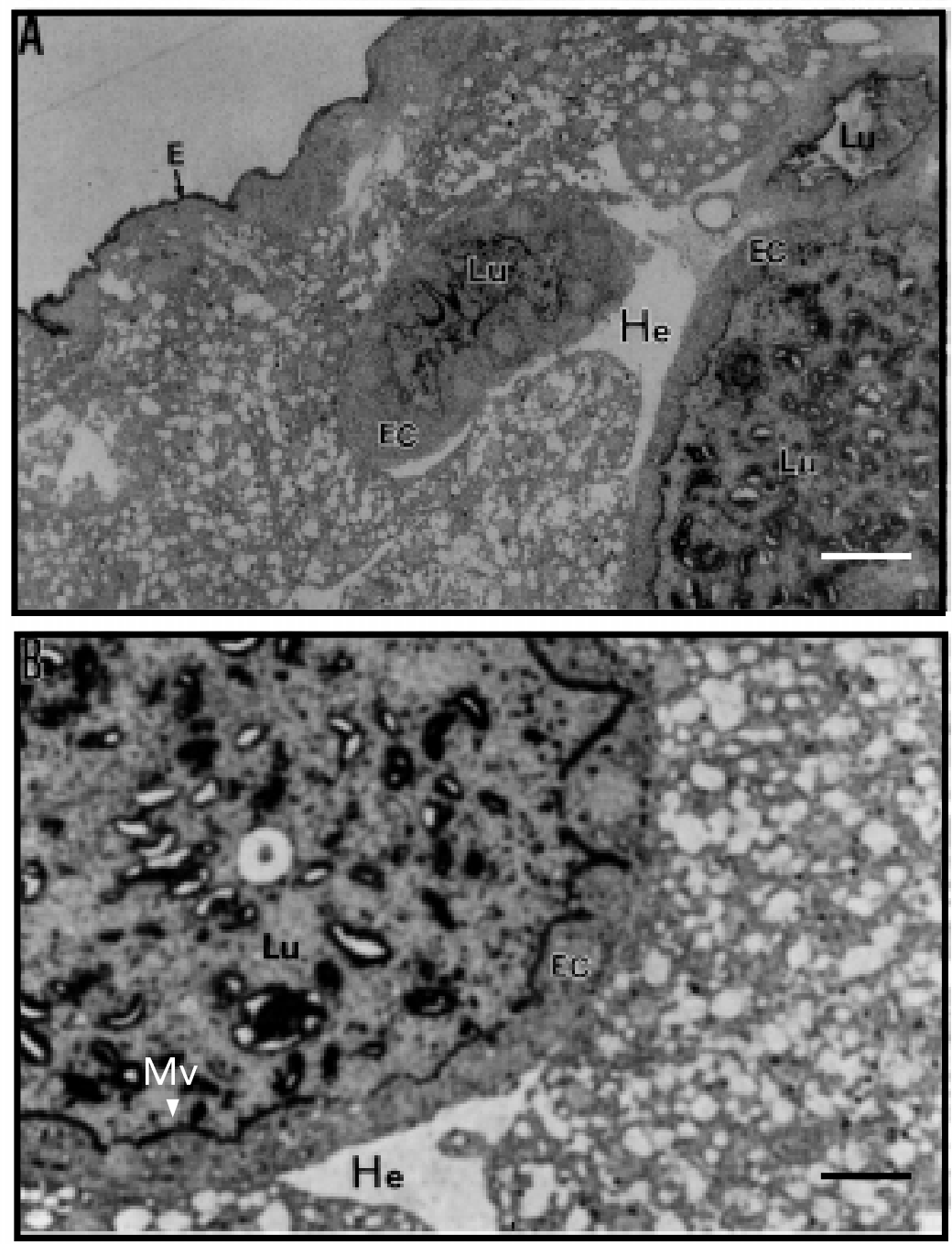

Figure 5 - Immunohistochemical detection of vicilins in microsections of whole larvae of Callosobruchus maculatus reared on resistant (IT81D-1045) cowpea seeds and immunolabeled with anti-vicilin IgG. Lu = Lumen, $\mathrm{Mv}=$ microvilli, $\mathrm{He}=$ hemolymph, $\mathrm{E}=$ epidermis, EC = gut epithelial cells. (A and B: Magnification: 7,800X and 15,600X; bar: 20 $\mu \mathrm{m}$ and $10 \mu \mathrm{m}$, respectively). show three cross-sections of the gut wall surrounding the intestinal lumen (Figure 5A). Three cross-sections appear in a single micrograph because the gut forms loops when the larvae are fixed and embedded. The epithelial cells show microvilli that were strongly labeled after immunostaining with anti-vicilin antibodies. The lumen contains strongly labeled material possibly corresponding to food particles in the process of being digested. The epidermis was also immunostained. Structures that we interpreted as gut epithelial cells did not contain vicilin immunolabeling, indicating that these proteins were not internalized by the cells. The hemolymph surrounding the gut was completely free of immunostaining, suggesting that no alteration of the structure of the midgut with disruption of the microvilli or abnormalities in epithelial cells had occurred.

How chitin-binding proteins, vicilins included, exert their deleterious effects on insect development is not known but one may speculate that these effects are mediated by the binding of the proteins to chitin in the peritrophic membrane that lines the midguts of insects. In insects that unequivocally show this membrane, various functions have been attributed to it like protection against bacterial and virus invasion and protection against microvillus damage caused by food $(30,31)$. Here we have shown by a qualitative color test that the C. maculatus larval midgut contains chitinous structures. In addition, thin sections of the larval midgut showed the presence of immunolabeled sites when an anti-chitin antibody was used. In agreement with the suggestion by Vats (29) and Terra (32), these structures in the midgut of bruchid larvae are not distinct but are localized at the boundaries of the microvilli and apparently do not delimit endo- and ectoperitrophic spaces.

In order to understand the mechanism of action of vicilins, we investigated the binding of these proteins to isolated membrane components of the midgut of C. maculatus 
larvae. Vicilins from resistant seeds reacted most intensely with membrane components and were desorbed from these by soluble chitosan and $0.1 \mathrm{~N} \mathrm{HCl}$. Similar results were obtained by Sales et al. (14) who observed that resistant vicilins were more strongly retained by a chitin matrix. Immunocytochemical analysis showed that the sites of binding of anti-vicilin IgG are the same as those observed with anti-chitin IgG in the midgut of large larvae reared on susceptible seeds and larval sections of small larvae reared on resistant seeds.

In spite of their very high degree of sequence homology, vicilins of legume seeds (27) show different digestibility rates when treated with several proteases (33). Sales et al. (12) reported that vicilins from resistant cowpea seeds were more refractory to diges- tion than vicilins from susceptible cowpea seeds. The antimetabolic effects of resistant or variant cowpea vicilins may be related to these low digestion rates and to their association with chitin-containing structures of the insect's midgut. The result of both of these phenomena is the impairment of nutrient uptake by midgut cells resulting in a lower rate of development of $C$. maculatus larvae in seeds of $V$. unguiculata IT81D1045 .

\section{Acknowledgments}

We thank Dr. P. Marinho, Department of Biology and Genetics, Federal University of Rio Grande do Norte, for a critical reading of this manuscript.

\section{References}

1. Singh SR \& Rachie KO (1985). Cowpea Research, Production and Utilization. J ohn Wiley \& Sons, Chichester.

2. May $\mathrm{PH}$, Teixeira $\mathrm{SM} \&$ Santana $\mathrm{CA}$ (1988). Cowpea production and economic importance in Brazil. In: Watt EE \& Araújo J PP (Editors), Cowpea Research in Brazil. IITA/EMBRAPA, Ibadan, Nigeria, 31-62.

3. Singh BB, Singh SR \& Adaji O (1985). Bruchid resistance in cowpea. Crop Science, 25: 736-739.

4. Singh BB \& Singh SR (1990). Breeding for bruchid resistance in cowpea. In: Fuji K, Gatehouse AMR \& Yoshida T (Editors), Bruchids and Legumes: Economy, Ecology and Coevolution. Kluwer, Dordrecht, 219-228.

5. Gatehouse AMR, Gatehouse J A, Dobie P, Kilminster AM \& Boulter D (1979). Biochemical basis of insect resistance in Vigna unguiculata. J ournal of the Science of Food and Agriculture, 30: 948-958.

6. Gatehouse AMR \& Boulter D (1983). Assessment of the antimetabolic effects of trypsin inhibitors from cowpea (Vigna unguiculata) and other legumes on the development of the bruchid beetle, Callosobruchus maculatus. J ournal of the Science of Food and Agriculture, 34: 345350.

7. Baker TA, Nielsen SS, Shade RE \& Singh BB (1989). Physical and chemical at- tributes of cowpea lines resistant and susceptible to Callosobruchus maculatus (F.) (Coleoptera: Bruchidae). J ournal of Stored Products Research, 25: 1-8.

8. Xavier-Filho J, Campos FAP, Ary MB, Silva CP, Carvalho MMM, Macedo MLR, Lemos FJ A \& Grant G (1989). Poor correlation between the levels of proteinase inhibitors found in seeds of different cultivars of cowpea (Vigna unguiculata) and resistance/susceptibility to predation by Callosobruchus maculatus. J ournal of Agricultural and Food Chemistry, 37: 11391143.

9. Fernandes KVS, Sabelli PA, Barrat DHP, Richardson M, Xavier-Filho J \& Shewry PR (1993). The resistance of cowpea seeds to bruchid beetles is not related to levels of cysteine proteinase inhibitors. Plant Molecular Biology, 23: 215-219.

10. Reis $C M$, Calvet MM, Sales MP, Fernandes KVS, Gomes VM \& Xavier-Filho J (1997). $\alpha$-Amylase inhibitors of legume seeds and their involvement in the resistance to the bruchid beetles. Arquivos de Biologia e Tecnologia, 40: 413-418.

11. Xavier-Filho J (1991). The resistance of seeds of cowpea (Vigna unguiculata) to the cowpea weevil (Callosobruchus maculatus). Memórias do Instituto Oswaldo Cruz, 86: 75-77.

12. Sales MP, Macedo MRL \& Xavier-Filho J
(1992). Digestibility of cowpea (Vigna unguiculata) vicilins by pepsin, papain and bruchid midgut proteinases. Comparative Biochemistry and Physiology, 103: 945950.

13. Macedo MRL, Andrade LBS, Moraes RA \& Xavier-Filho J (1993). Vicilin variants and the resistance of cowpea (Vigna unguiculata) seeds to the cowpea weevil (Callosobruchus maculatus). Comparative Biochemistry and Physiology, 105C: 89-94.

14. Sales MP, Fernandes KVS, Gomes VM \& Xavier-Filho J (1996). Chitin-binding proteins from cowpea (Vigna unguiculata) seeds. Brazilian J ournal of Medical and Biological Research, 29: 319-326.

15. Firmino F, Fernandes KVS, Sales MP, Gomes VM, Miranda MRA, Domingues SJ S \& Xavier-Filho J (1996). Cowpea (Vigna unguiculata) vicilins associate with putative chitinous structures in midgut and feces of the bruchid beetles Callosobruchus maculatus and Zabrotes subfasciatus. Brazilian J ournal of Medical and Biological Research, 29: 749-756.

16. Gomes VM, Blanco-Labra A, Sales MP, Fernandes KVS, Cordeiro RA \& XavierFilho J (1997). Vicilin storage proteins from cowpea (legume) seeds inhibit fungal development. J ournal of Agricultural and Food Chemistry, 45: 4110-4115.

17. Yunes ANA, Andrade MT, Sales MP, 
Moraes RA, Fernandes KVS, Gomes VM \& Xavier-Filho J (1998). Legume seed vicilins (7S storage proteins) interfere with the development of the cowpea weevil [Callosobruchus maculatus (F.)]. Science of Food and Agriculture, 76: 111-116.

18. Chrispeels MJ \& Raikhel NV (1991). Lectin, lectin genes and their role in plant defense. Plant Cell, 3: 1-9.

19. Macedo MRL, Fernandes KVS, Sales MP \& Xavier-Filho J (1995). Purification and properties of storage proteins (vicilins) from cowpea (Vigna unguiculata) seeds which are susceptible or resistant to the bruchid beetle. Brazilian J ournal of Medical and Biological Research, 28: 183-190.

20. Bradford MM (1976). A rapid and sensitive method for the quantitation of microgram quantities of protein utilising the principle of protein-dye binding. Analytical Biochemistry, 72: 248-254.

21. Laemmli UK (1970). Cleavage of structural proteins during the assembly of the head of bacteriophage T4. Nature, 227: 680-685.
22. Towbin H, Stachelin NT \& Gordon J (1979). Electrophoretic transfer of proteins from polyacrylamide gels to nitrocellulose sheets; procedures and some applications. Proceedings of the National Academy of Sciences, USA, 176: 43504354.

23. Roger HJ \& Perkins HR (1968). Cell Walls of Filamentous Fungi. Chapter IX. E. \& F.N. Spon Ltd., London, 153-160.

24. Pedalino M, Paino-d'Urzo M, Delle Done G, Grillo S \& Rao R (1992). The structure of cowpea (Vigna unguiculata L. Walp) seed storage proteins. Seed Science and Technology, 20: 223-231.

25. Higgins TJ V (1984). Synthesis and regulation of major proteins in seeds. Annual Review of Plant Physiology, 35: 191-221.

26. Shewry PR (1995). Plant storage proteins. Biological Reviews, 70: 375-426.

27. Casey R, Domeney C \& Ellis N (1986). Legume storage proteins and their genes. In: Miflin BJ (Editor), Oxford Surveys of Plant Molecular Biology and Cell Biology. Vol. 3. Oxford University Press, Oxford, 1-
95.

28. Khan RI, Gatehouse J A \& Boulter D (1980). The seed proteins of cowpea (Vigna unguiculata L. Walp). J ournal of Experimental Botany, 31: 1599-1611.

29. Vats LK (1976). Alimentary canal in bruchid larvae (Bruchidae:Coleoptera). Research Bulletin (Science) of the Panjab University Science, 27: 103-106.

30. Peters W (1992). Peritrophic Membranes. Springer Verlag, Berlin.

31. Walters LL, Irons KP, Guzman H \& Tesh RB (1993). Formation and composition of peritrophic membranes in the sand fly, Phlebotomus perniciosus (Diptera: Psychodidae). J ournal of Medical Entomology, 30: 179-198.

32. Terra WR (1990). Evolution of digestive system of insects. Annual Review of Entomology, 35: 181-200.

33. Deshpande SS \& Damodaran S (1989). Structure-digestibility relationships of legume 75 storage proteins. J ournal of Food Science, 54: 108-113. 